\title{
Reguladores vegetais e atividade de invertases em cana-de-açúcar em meio de safra
}

\author{
Growth regulators and activity invertases in the middle of the cropping season
}

\author{
Glauber Henrique Pereira Leite ${ }^{\mathrm{I}}$ Carlos Alexandre Costa Crusciol*I \\ Giuseppina Pace Pereira Lima ${ }^{\text {II }}$ Marcelo de Almeida Silva ${ }^{\text {II }}$
}

\section{RESUMO}

O objetivo neste trabalho foi a avaliação da atividade das invertases ácida e neutra e a função que essas exercem no controle do acúmulo de sacarose em cana-de-açúcar, variedade SP80-3280, decorrente da aplicação de reguladores vegetais no meio de safra, em Igaraçu do Tietê (SP). O experimento foi conduzido em cana soca, em safras consecutivas (2004 e 2005). O delineamento experimental utilizado foi em blocos casualizados, com cinco repetições. Os tratamentos foram constituídos da aplicação de quatro reguladores vegetais da classe dos retardadores do crescimento (Etefon, Etil-trinexapac, $\mathrm{KNO}_{3}$ e $\mathrm{KNO}_{3}+$ Boro) e uma testemunha (maturação natural), comercialmente encontrados como Ethrel, Moddus, Krista Kana e Krista Kana Plus, respectivamente, adotando-se a dosagem

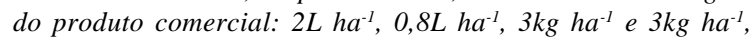
respectivamente, sem a adição de adjuvantes. Os reguladores vegetais promovem alterações de intensidades distintas $e$ significativas nos níveis enzimáticos das invertases ácida $e$ neutra. A eficiência agronômica dos maturadores foi afetada de forma significativa pelo clima e pela época de aplicação. Os tratamentos com maturadores, principalmente em 2004, cujas condições climáticas foram desfavoráveis à maturação natural, favoreceram o processo de maturação da cana-deaçúcar, implicando em melhorias da qualidade tecnológica dos colmos.

Palavras-chave: Saccharum spp., maturadores, etefon, etiltrinexapac, enzimas.

\section{ABSTRACT}

The objective of this research was to evaluate the activity of acid and neutral invertases in controling the storage of sucrose in sugarcane variety SP80-3280 due to plant regulators application in the middle of the cropping season in Igaraçu do Tietê (SP), Brazil. The experiment was carried out in ratoon cane (crop 2004 and 2005) in a randomized block design with five replications. The treatments consisted of four plant regulators application of the class of growth retainers (Ethephon, Ethyl.trinexapac, Potassium nitrate and Potassium nitrate + Boron) and a control (natural ripening), whose commercial products (c.p.) were Ethrel, Moddus, Krista Kana and Krista Kana Plus, with dosage of $2 L$ c.p. ha ${ }^{-1}, 0.8 L$ c.p. $h a^{-1}$, $3 \mathrm{~kg}$ c.p. ha $\mathrm{a}^{-1}$ and 3c.p. $\mathrm{kg} \mathrm{ha}^{-1}$, respectively, without adjuvants application. The growth regulators provide alterations of different and significant intensity in soluble acid invertase and neutral invertase levels enzymes. The agricultural efficiency of maturators was affected significatively by the weather and time of application. The treatments with maturators, were affected most in 2004, when wheater conditions were unfavourable to natural ripening, were favour the ripening sugarcane process implicating in improvement technological quality of stems.

Key words: Saccharum spp., maturators, ethephon, ethyltrinexapac, enzymes.

\section{INTRODUÇÃO}

Em diversas espécies vegetais, nas folhas (local considerado como fonte), ocorre a síntese de carboidratos, os quais são translocados para os tecidos (drenos) na forma de sacarose, para suprir o metabolismo e desenvolvimento vegetal e/ou para o acúmulo na forma de sacarose ou amido. Esses processos são acompanhados por constantes

\footnotetext{
I,Departamento de Produção Vegetal, Faculdade de Ciências Agronômicas, Universidade Estadual Paulista (UNESP), CP 237, 18610-307, Botucatu, SP, Brasil. E-mail: ghpleite@fca.unesp.br. E-mail: crusciol@fca.unesp.br. *Autor para correspondência.

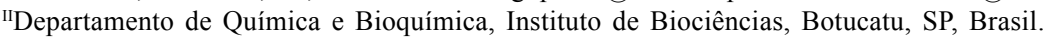

IIIAgência Paulista de Tecnologia dos Agronegócios (APTA), Regional Centro-oeste, Jaú, SP, Brasil
} 
mudanças nas relações fonte-dreno (ROITSCH \& GONZÁLEZ, 2004). O mecanismo do acúmulo ativo de sacarose é dependente da maturidade dos tecidos, isto é, há diferença entre tecidos maduros e imaturos devido, principalmente, à concentração de invertases e a necessidade de crescimento (ALEXANDER, 1973).

O metabolismo de partição e acúmulo de sacarose é vital em todas as fases do ciclo de vida vegetal e sua utilização como fonte de energia e de carbono requer sua hidrólise. As invertases quebram a sacarose em hexoses e, assim, disponibilizam às células carbono e energia para o processo de respiração, bem como energia para a síntese de numerosos compostos diferenciados. As invertases podem, ainda, estar envolvidas no transporte de sacarose a longas distâncias por criar o gradiente de concentração de sacarose entre os sítios de carregamento e descarregamento do floema, revelando função fundamental na partição dos fotossintetizados entre armazenamento e crescimento (ESCHRICH, 1980).

A invertase ácida solúvel (SAI) é composta pelo somatório das invertases do espaço externo, ou seja, parede celular e do vacúolo, sendo encontrada em quantidade superior e praticamente em tecidos imaturos. A atividade dessa isoenzima pode ser alta ou baixa, respectivamente, em condições favoráveis ao crescimento ou em condições desfavoráveis, como por exemplo, estresse hídrico, fotoperiodo curto, temperaturas baixas e aplicação de maturadores (GAYLER \& GLASZIOU, 1972; LEGENDRE, 1975). As flutuações, nos teores de açúcar, durante o crescimento vegetal é conseqüência do nível da enzima SAI (GAYLER \& GLASZIOU, 1972; LINGLE, 1999), uma vez que a SAI apresenta relação estreita e inversa com o conteúdo de sacarose e açúcares totais, corroborando com outros autores (HAWKER, 1985; SU et al., 1992; ZHU et al., 1997; TERAUCHI et al., 2000).

A expansão celular dos tecidos imaturos requer hexoses como fonte de energia e carbono e depende da direção da força de alongamento celular, conseqüência da manutenção da pressão osmótica celular e do aumento da extensibilidade da parede celular. Portanto, diversos estudos evidenciam a atuação da SAI no processo de osmorregulação (GAYLER \& GLASZIOU, 1972; GIBEAUT et al., 1990). Nos tecidos maduros do colmo, onde os processos de crescimento estão praticamente finalizados, ocorre declínio da concentração da SAI e, então, a invertase neutra (NI) torna-se predominante, situando-se, aparentemente, no citoplasma. Essa enzima, com o baixo nível da SAI, governa o acúmulo ativo de sacarose no vacúolo. Posteriormente, nos tecidos com maior maturidade, que apresentam teores de sacarose em torno de 15 a 20\%, há armazenamento de sacarose nos espaços intercelulares (LINGLE, 1999).

Os maturadores, definidos como reguladores vegetais, agem alterando a morfologia e a fisiologia da planta, podendo levar a modificações qualitativas e quantitativas na produção. Podem atuar, para promover a diminuição do crescimento da planta, possibilitar incrementos no teor de sacarose nos entrenós, precocidade de maturação, aumentar a produtividade de açúcar, e também atuar sobre as enzimas (invertases), que catalisam o acúmulo de sacarose nos colmos (CASTRO, 1999; MARTINS \& CASTRO, 1999). O maturador Etil-trinexapac reduz os níveis endógenos da forma ativa da giberelina ácida, $\mathrm{GA}_{1}$, por suprimir sua biossíntese à GA $\mathrm{G}_{20}$ (RESENDE et al., 2000), sendo que as giberelinas ácidas, em diversas espécies vegetais, têm importante função regulatória na atividade das invertases, envolvidas principalmente com a taxa de elongação dos colmos. (TYMOWSKALALANNE \& KREIS, 1998).

Nesse contexto, no presente trabalho, o objetivo foi a avaliação da atividade das invertases ácida e neutra e a função que essas exercem no controle do acúmulo de sacarose em cana-de-açúcar, variedade SP80-3280, decorrente da aplicação de reguladores vegetais no meio de safra, em Igaraçu do Tietê (SP).

\section{MATERIAL E MÉTODOS}

O experimento foi conduzido em cana soca ( $2^{\circ}$ corte realizado em 30/04/2003), por dois anos consecutivos (2004 e 2005), na Fazenda São Joaquim, no Município de Igaraçu do Tietê, Estado de São Paulo (latitude de $22^{\circ} 38^{\prime} 45^{\prime}$ 'S, longitude $48^{\circ} 36^{\prime} 29^{\prime \prime} \mathrm{W}$ e altitude de $620 \mathrm{~m})$. Os dados climáticos mensais, referentes às temperaturas máxima, média e mínima, precipitação pluvial e velocidade do vento durante o período de condução do experimento, coletados na Estação Metereológica da Fazenda São Joaquim, estão na figura 1.

O delineamento experimental utilizado foi o de blocos casualizados, com cinco repetições. Os tratamentos foram constituídos de uma testemunha (maturação natural) e da aplicação de quatro reguladores vegetais da classe dos retardantes do crescimento (Etefon, Etil-trinexapac, $\mathrm{KNO}_{3}$ e $\mathrm{KNO}_{3}+$ Boro), comercialmente encontrados como Ethrel, Moddus, Krista Kana e Krista Kana Plus, respectivamente, adotando-se a dosagem recomendada pelos fabricantes, ou seja, 2L ha ${ }^{-1}, 0,8 \mathrm{~L} \mathrm{ha}^{-1}, 3 \mathrm{~kg} \mathrm{ha}^{-1}$ e $3 \mathrm{~kg} \mathrm{ha}^{-1}$, respectivamente, sem a adição de adjuvantes. Cada parcela foi constituída por oito linhas de cana-de-açúcar de $10 \mathrm{~m}$ de comprimento, espaçadas de 1,5m. Contudo, 


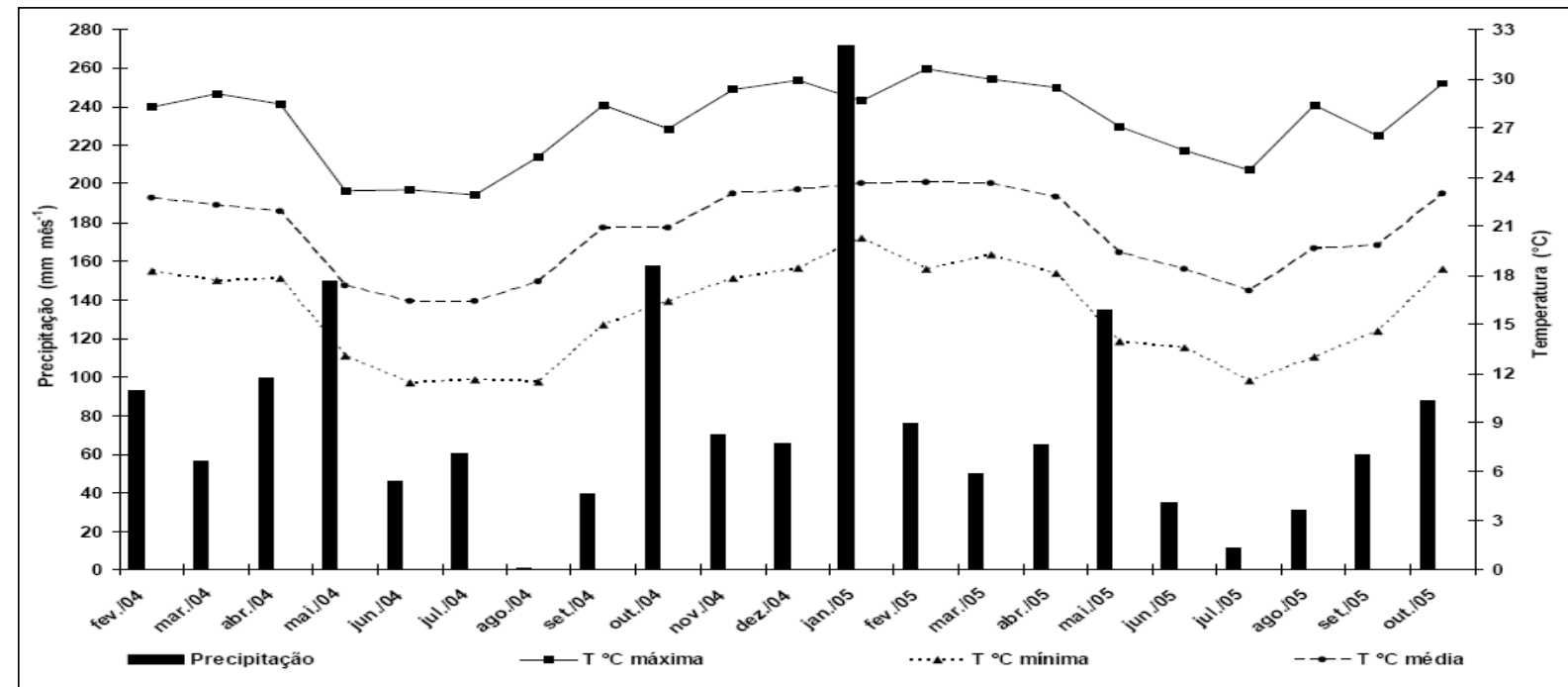

Figura 1 - Precipitação e temperatura do ar (máxima, média e mínima) registrada durante o período de condução do experimento na Estação Metereológica da Fazenda São Joaquim nas safras 2004 e 2005, Igaraçu do Tietê, SP.

para as avaliações foram consideradas as seis linhas centrais, desprezando-se $1 \mathrm{~m}$ nas extremidades, perfazendo uma área útil de $72 \mathrm{~m}^{2}$. A aplicação dos produtos, de acordo com os tratamentos, foi realizada em 10/05/2004 e 04/08/2005, utilizando-se equipamento costal pressurizado $\left(\mathrm{CO}_{2}\right)$, com barra de $6 \mathrm{~m}$ de comprimento em forma de $\mathrm{T}$, contendo seis pontas de pulverização AXI 11002, sendo a pressão de trabalho de 50 PSI para a vazão de $100 \mathrm{~L} \mathrm{ha}^{-1}$.

A variedade SP80-3280 tem como características: alto teor de sacarose e produtividade em soqueira, maturação média para tardia, perfilhamento intermediário, florescimento, no entanto acompanhado por pouco chochamento (COOPERATIVA DE PRODUTORES DE CANA,AÇÚCAR E ÁLCOOL DO ESTADO DE SÃO PAULO, 1997). No período experimental, foram estabelecidas quatro épocas de amostragem para as mensurações bioquímicas $(0,30$, 60 e 90 dias após aplicação (DAA)). A determinação tecnológica foi realizada aos $0,15,30,45,60,75,90$ e 174 DAA, totalizando oito épocas em 2004, e aos 0, 15 , 30, 60 e 90 DAA, totalizando cinco épocas em 2005.

$\mathrm{Na}$ área útil, estabeleceu-se $1 \mathrm{~m}$ aleatório a cada época de amostragem, sendo os colmos coletados, submetidos ao desponte de altura da gema apical, à desfolha e encaminhados para o laboratório de Análises Bioquímicas do Departamento de Química e Bioquímica do Instituto de Biociências (IB/UNESP) e para o laboratório de Bebidas do Departamento de Gestão e Tecnologia Agroindustrial da Faculdade de Ciências Agronômicas (FCA/UNESP), campus de Botucatu (SP), para realização das determinações bioquímicas e tecnológicas, nesse caso, segundo a metodologia do Sistema de Pagamento de Cana pelo Teor de Sacarose (SPCTS), conforme atualizações semestrais da Consecana, descritas em FERNANDES (2003), sendo considerado o parâmetro pol cana (PCC).

As determinações das invertases ácida solúvel (SAI) e neutra (NI) foram realizadas após a moagem dos colmos para obtenção do extrato bruto. Conforme adaptação às metodologias descritas por HATCH et al. (1963), RICARDO \& AP REES (1970) e VIEIRA (1983), foram preparados os extratos específicos das isoenzimas. Alíquotas de $5 \mathrm{~mL}$ (obtidas após a filtragem do caldo em baixa temperatura) foram tomadas e acrescidas a $5 \mathrm{~mL}$ de tampão mercaptoetanol $1 \mathrm{mM}, \mathrm{pH} 7,5$. Após centrifugação a $10000 \mathrm{rpm}$, por 30 minutos a $4^{\circ} \mathrm{C}$, o sobrenadante foi separado e ao precipitado acrescido mais $5 \mathrm{~mL}$ de tampão de fosfato de sódio, $5 \mathrm{mM}$, pH 7,0, o qual foi novamente centrifugado a $10000 \mathrm{rpm}$, por 30 minutos, a $4^{\circ} \mathrm{C}$. A atividade da NI e da SAI também foram realizadas de acordo com adaptação às metodologias propostas por HATCH et al. (1963), RICARDO \& AP REES (1970) e VIEIRA (1983). Para reação da NI foram tomados 1,25mL do extrato, $6,25 \mathrm{~mL}$ de tampão fosfato de sódio $50 \mathrm{mM}$, $\mathrm{pH} 7,5$ e 2,5mL de sacarose $200 \mathrm{mM}$. O sistema de reação ocorreu em banho-maria $\left(37^{\circ} \mathrm{C}\right)$ por 30 minutos. Após resfriamento, acrescentou-se $1 \mathrm{~mL}$ do reativo de Somogi e o meio foi levado para banho maria $\left(37^{\circ} \mathrm{C}\right)$ por mais 10 minutos. Posteriormente, adicionou-se $1 \mathrm{~mL}$ do reativo de Nelson, sendo feita a leitura em espectrofotômetro UV/VIS, a 530nm. Para reação da SAI, foram tomados $1,25 \mathrm{~mL}$ do extrato, $6,25 \mathrm{~mL}$ de tampão acetato de sódio

Ciência Rural, v.39, n.3, mai-jun, 2009. 
$50 \mathrm{mM}, \mathrm{pH} 4,5$ e $2,5 \mathrm{~mL}$ de sacarose $200 \mathrm{mM}$. O sistema de reação ocorreu em banho maria $\left(37^{\circ} \mathrm{C}\right)$, por 30 minutos. Após resfriamento, acrescentou-se $1 \mathrm{~mL}$ do reativo de Somogyi e novamente incubado em banhomaria $\left(37^{\circ} \mathrm{C}\right)$ por mais 10 minutos. Posteriormente, adicionou-se $1 \mathrm{~mL}$ do reativo de Nelson, sendo feita a leitura em espectrofotômetro UV/VIS, a $530 \mathrm{~nm}$.

Os resultados foram submetidos à análise de variância e à análise de regressão, adotando-se, como critério para escolha do modelo, a magnitude dos coeficientes de regressão, significativos a $5 \%$ de probabilidade de erro pelo teste $t$.

\section{RESULTADOS E DISCUSSÃO}

Na safra 2004, a disponibilidade hídrica e térmica favoreceu o desenvolvimento vegetativo da cana-de-açúcar, tendo em vista a disponibilidade hídrica nos meses de março a julho e declínio da temperatura nos meses de maio a agosto, respectivamente (Figura 1). Por outro lado, na safra 2005, o processo de maturação natural foi favorecido pela menor precipitação pluvial no intervalo de maio a julho, com pequenas diferenças em relação à safra anterior, quanto à disponibilidade térmica, referente à média mensal (Figura 1).

Na safra 2004 ,a atividade da isoenzima ácida mostrou-se superior à atividade da isoenzima neutra, enquanto na safra subseqüente, de modo geral, os níveis da isoenzima neutra superaram os níveis da isoenzima ácida. Todavia, no período experimental, os tratamentos afetaram, de forma significativa, o comportamento enzimático (Figura 2). Tal resultado pode ser explicado, provavelmente, pela condição climática de cada período (Figura 1), associado à época de aplicação dos tratamentos. O ambiente favorável ao desenvolvimento vegetativo da planta, em 2004 (Figura 1), acarretou na necessidade de açúcares (glicose e
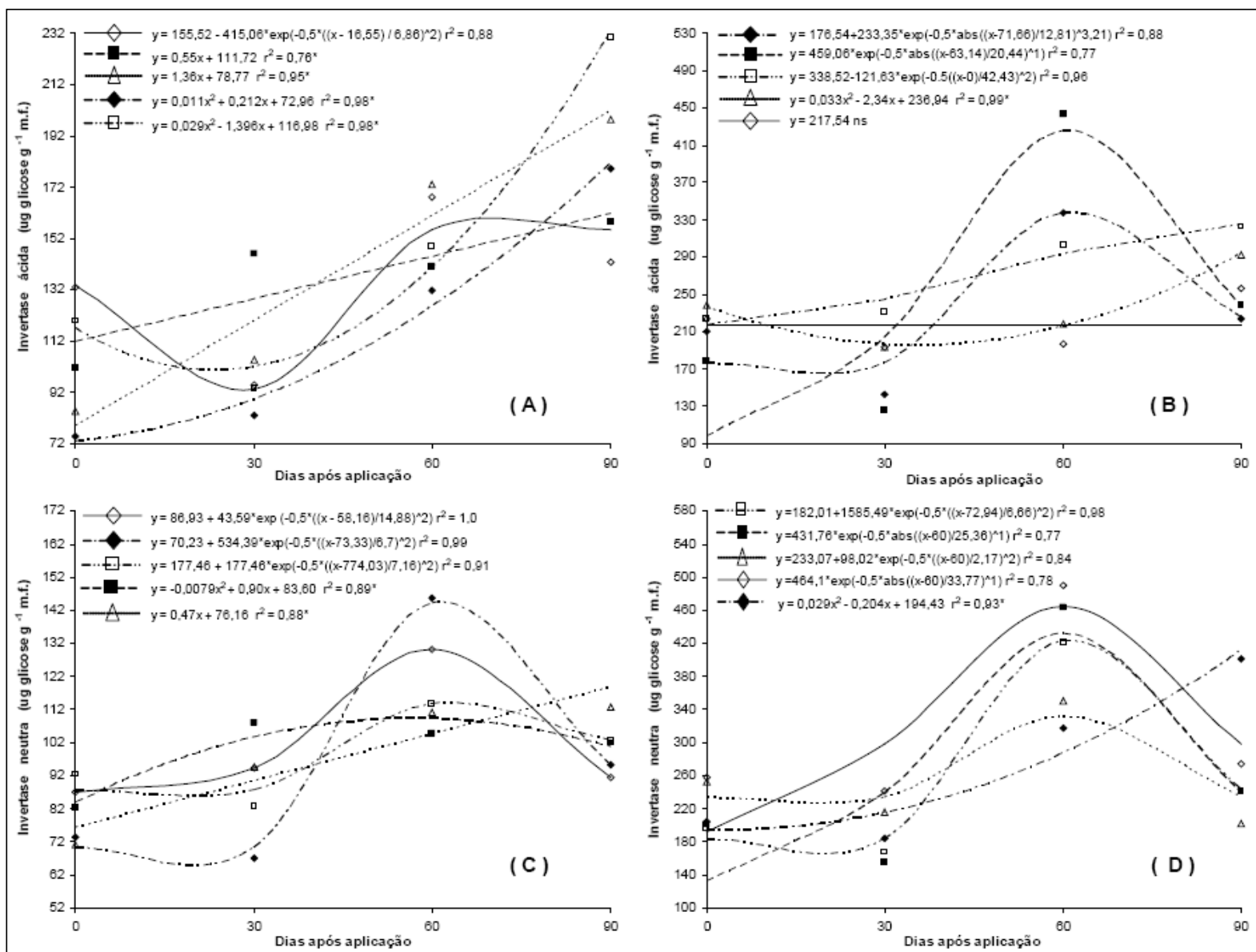

Figura 2 - Atividade de invertases ácida e neutra ( $\mu \mathrm{g}$ glicose $100 \mathrm{~g}^{-1}$ matéria fresca) em função da aplicação dos tratamentos

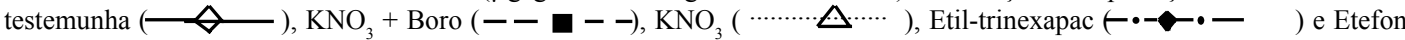
(-•-••• na variedade de cana-de-açúcar SP80-3280, Igaraçu do Tietê, SP, na safra 2004 (A, C) e na safra 2005 (B, D).

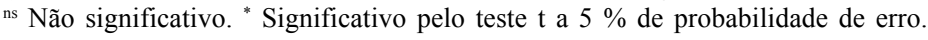


frutose) para a manutenção do metabolismo e elevada atividade da SAI, enquanto, em 2005, o ambiente favorável ao processo de maturação natural (Figura 1), aliado ao controle genético do processo (intrínseco à variedade) e à aplicação tardia dos tratamentos contribuiu para os altos níveis da NI (Figura 2).

Os resultados estão de acordo com VIEIRA et al. (1996b), os quais encontraram nos colmos de canade-açúcar, variedade CB41-76, níveis elevados da isoenzima ácida em relação à neutra, sugerindo a atuação dessa enzima na regulação do crescimento de tecidos imaturos. Por outro lado, outros resultados de pesquisas determinaram elevados níveis de atividade da NI em relação à SAI, em colmos de diferentes variedades de cana-de-açúcar, além da tendência de declínio com o desenvolvimento fisiológico vegetal e tal relação pode estar estreitamente ligada à capacidade de acumular sacarose (HATCH \& GLASZIOU, 1963; RICARDO \& SOVIA, 1974; SUZUKI, 1983; VIEIRA et al., 1996a).

Os níveis da SAI, na safra 2004, foram crescentes ao longo das épocas de amostragem para o tratamento $\mathrm{KNO}_{3}$ e $\mathrm{KNO}_{3}$ + Boro, com ajuste linear, enquanto para os tratamentos Etefon e Etil-trinexapac, houve ajuste quadrático, determinando-se as mínimas atividades da SAI aos $24\left(100,18 \mu \mathrm{g}\right.$ de glicose $100 \mathrm{~g}^{-1}$ de matéria fresca) e aos $10\left(76,18 \mu \mathrm{g}\right.$ de glicose $100 \mathrm{~g}^{-1}$ de matéria fresca) DAA, respectivamente (Figura 2A). Por outro lado, a maturação natural (testemunha) foi caracterizada pela reduzida atividade da SAI aos 18 DAA $\left(52,20 \mu \mathrm{g}\right.$ de glicose $100 \mathrm{~g}^{-1}$ de matéria fresca) e posterior nível crescente até os 63DAA $(155,52 \mu \mathrm{g}$ de glicose $100 \mathrm{~g}^{-1}$ de matéria fresca) com sua estabilização (Figura 2A).

Com relação à atividade da NI, na safra 2004, os tratamentos $\mathrm{KNO}_{3}$ + Boro e $\mathrm{KNO}_{3}$ foram ajustados a modelos quadrático e linear, respectivamente, com máxima atividade da NI aos 57 DAA, para o tratamento $\mathrm{KNO}_{3}+$ Boro cujo valor calculado foi de $109,23 \mu \mathrm{g}$ de glicose $100 \mathrm{~g}^{-1}$ de matéria fresca (Figura $2 \mathrm{C}$ ). Por outro lado, os níveis da enzima NI mostraram-se estáveis até, aproximadamente $23\left(89,60 \mu \mathrm{g}\right.$ de glicose $100 \mathrm{~g}^{-1} \mathrm{de}$ matéria fresca), $34\left(70,23 \mu \mathrm{g}\right.$ de glicose $100 \mathrm{~g}^{-1}$ de matéria fresca) e 36 DAA $\left(87,61 \mu \mathrm{g}\right.$ de glicose $100 \mathrm{~g}^{-1}$ de matéria fresca) para a maturação natural (testemunha) e para os tratamentos Etil-trinexapax e Etefon, respectivamente, e posteriores níveis crescentes, com máxima atividade aos $58\left(130,52 \mu \mathrm{g}\right.$ de glicose $100 \mathrm{~g}^{-1} \mathrm{de}$ matéria fresca), $71\left(159,75 \mu \mathrm{g}\right.$ de glicose $100 \mathrm{~g}^{-1}$ de matéria fresca) e 48 DAA $\left(108,45 \mu \mathrm{g}\right.$ de glicose $100 \mathrm{~g}^{-1}$ de matéria fresca), seguidos de declínio (Figura 2C).

Na safra 2005, os tratamentos influenciaram significativamente, a atividade da SAI, com exceção da maturação natural (testemunha) e do tratamento Etil- trinexapac (Figura 2B). O tratamento $\mathrm{KNO}_{3}$ foi ajustado a modelo quadrático, com menor atividade da SAI aos 35 DAA $\left(195,47 \mu \mathrm{g}\right.$ de glicose $100 \mathrm{~g}^{-1}$ de matéria fresca), enquanto para o tratamento Etefon, os níveis da SAI foram elevados com o transcorrer das épocas de amostragem, com atividade inicial e final de $216,89 \mathrm{e}$ $325,69 \mu \mathrm{g}$ de glicose $100 \mathrm{~g}^{-1}$ de matéria fresca aos 0 e 90 DAA, respectivamente (Figura 2B). Por outro lado, para o tratamento $\mathrm{KNO}_{3}+$ Boro, o nível da NI foi crescente

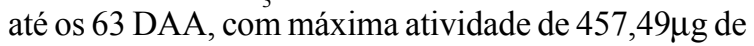
glicose $100 \mathrm{~g}^{-1}$ de matéria fresca e posterior declínio (Figura 2B).

A atividade da isoenzima neutra foi afetada de forma significativa pelos tratamentos na safra 2005 (Figura 2D), sendo determinados para a maturação natural (testemunha) e para os tratamentos $\mathrm{KNO}_{3}+$ Boro e Etefon, níveis crescentes até aproximadamente 60 DAA cuja atividade máxima calculada foi de 464,10, 431,76 e $403,57 \mu \mathrm{g}$ de glicose $100 \mathrm{~g}^{-1}$ de matéria fresca, respectivamente, com posterior declínio. Com relação ao tratamento $\mathrm{KNO}_{3}$, a atividade enzimática foi estável até 48 DAA $\left(233,07 \mu \mathrm{g}\right.$ de glicose $100 \mathrm{~g}^{-1}$ de matéria fresca), posterior nível crescente até $60 \mathrm{DAA}(331,09 \mu \mathrm{g}$ de glicose $100 \mathrm{~g}^{-1}$ de matéria fresca) seguido de reduzida atividade (Figura 2D).

Há relatos, na literatura, de redução na atividade da SAI sob condições de baixas temperaturas e sob a ocorrência do processo de maturação da canade-açúcar, correlacionando-a com o aumento na concentração de sacarose (ZHU et al., 1997; TERAUCHI et al., 2000). No entanto, outros autores atribuem à capacidade efetiva de armazenamento de sacarose nos colmos aos elevados níveis da NI em relação à SAI e à correlação significativa entre o teor de sacarose e o nível de NI (HATCH \& GLASZIOU, 1963; RICARDO \& SOVIA, 1974; SUZUKI, 1983; ROSE \& BOTHA, 2000).

De maneira geral, os tratamentos envolvendo os maturadores favoreceram o processo de maturação da cana-de-açúcar (Figura 3), sendo a intensidade do acúmulo de sacarose nos colmos influenciada pela condição climática (Figura 1), pela época de aplicação dos tratamentos e pelo padrão genético da variedade quanto à maturação (característica intrínseca à variedade).

Os tratamentos proporcionaram incremento no teor de sacarose com o transcorrer das épocas de amostragem, sendo ajustados a modelos quadráticos e lineares, na safra 2004 e 2005, respectivamente, com exceção do tratamento Etefon em 2005 (Figura 3A e 3B). Em 2004, o máximo acúmulo de sacarose ocorreu aos 129, 130, 133, 142 e 150 DAA para os tratamentos $\mathrm{KNO}_{3}+$ Boro $(\mathrm{PCC}=15,80 \%)$, Etil-trinexapac $(\mathrm{PCC}=15,40 \%)$, Etefon $(\mathrm{PCC}=15,70$ 

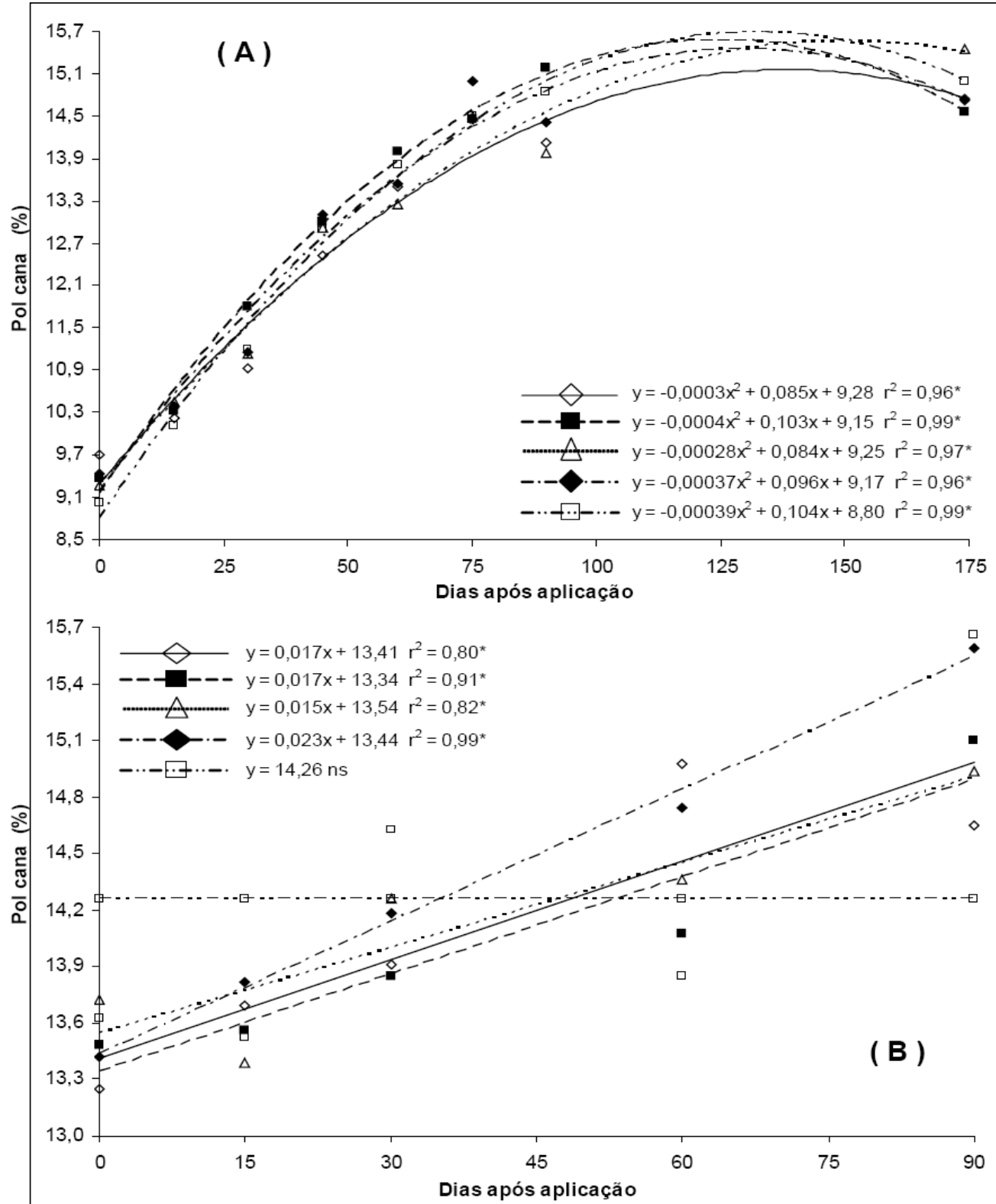

Figura 3 - Pol cana (\%) em função da aplicação dos tratamentos testemunha (ـ乞 $\mathrm{KNO}_{3}(\cdots \cdots \cdot \cdots \cdots)$, Etil-trinexapac ( $\left.\bullet \bullet-\bullet-\right)$ e Etefon $(-\bullet \bullet \bullet-)$ na variedade de cana-de-açúcar SP80-3280, Igaraçu do Tietê, SP, na safra 2004 (A) e na safra 2005 (B). " ${ }^{\text {ns }}$ Não significativo. " Significativo pelo teste t a $5 \%$ de probabilidade de erro.

$\%)$, testemunha $(\mathrm{PCC}=15,30 \%)$ e $\mathrm{KNO}_{3}(\mathrm{PCC}=15,60$ $\%$ ), respectivamente (Figura $3 \mathrm{~A}$ ); por outro lado, na safra subseqüente, não foi possível determinar o ponto de máximo de acúmulo de sacarose nos colmos, conforme as épocas de amostragem preestabelecidas (Figura 3B).

Pelas figuras 2 e 3, pode-se inferir que os tratamentos, principalmente na safra 2004, possibilitaram explorar, de forma significativa, o potencial genético da variedade de cana-de-açúcar
SP80-3280 em acumular sacarose, provavelmente, devido à condição climática (Figura 1) desfavorável à maturação natural e à época de aplicação.

\section{CONCLUSÕES}

Os reguladores vegetais promovem alterações de intensidades distintas e significativas nos níveis enzimáticos das invertases ácida e neutra. 
A eficiência agronômica dos maturadores foi afetada, de forma significativa, pelo clima e pela época de aplicação. No entanto, principalmente na safra 2004, em função das condições climáticas favoráveis ao desenvolvimento vegetativo da cultura, os maturadores favoreceram o processo de maturação da cana-de-açúcar, implicando em melhorias da qualidade tecnológica dos colmos.

\section{AGRADECIMENTOS}

À Fundação de Amparo à Pesquisa do Estado de São Paulo (Fapesp), pela concessão de bolsa de estudo a Glauber Henrique Pereira Leite. Ao Conselho Nacional de Desenvolvimento Científico e Tecnológico (CNPq), pela bolsa de produtividade em pesquisa a Carlos Alexandre Costa Crusciol. Ao Grupo COSAN - Unidade Barra (Usina da Barra), pela permissão de realização do experimento em sua área experimental.

\section{REFERÊNCIAS}

ALEXANDER, A.G. Sugarcane physiology. Amsterdam: Elsevier, 1973. 752p.

CASTRO, P.R.C. Maturadores químicos em cana-de-açúcar. Saccharum, v.1, p.12-16, 1999.

COOPERATIVA DE PRODUTORES DE CANA, AÇÚCAR E ÁlCOOL DO ESTADO DE SÃO PAUlO LTDA. Sexta geração de variedades de cana-de-açúcar Copersucar. Piracicaba, 1997. n.p. (Boletim Técnico COPERSUCAR - ed. especial).

ESCHRICH, W. Free space invertase, its possible role in phloem unloading. Ber Dtsch Bot Ges, n.93, p.363-378, 1980.

FERNANDES, A.C. Cálculos na agroindústria da canade-açúcar. Piracicaba: STAB, 2003. 240p.

GAYLER, K.R.; GLASZIOU, K.T. Physiological functions of acid and neutral invertases in growth and sugar storage in sugar cane. Physiol Plant, v.27, p.25-31, 1972.

GIBEAUT, D.M. et al. Cell wall and enzyme changes during graviresponse of the leaf-sheat pulvinus of oat (Avena sativa). Plant Physiol, n.94, p.411-416, 1990.

HATCH, M.D.; GLASZIOU, K.T. Sugar accumulation cycle in sugarcane. II. Relationship of invertase activity to sugar content and growth rate in storage tissue of plant grown in controlled environments. Plant Physiol, v.38, p.344-348, 1963.

HATCH, M.D. et al. Sugar accumulation cycle in sugarcane. I. Studies on enzymes of the cycle. Plant Physiol, v.38, p.338$343,1963$.

HAWKER, J.S. Sucrose. In: DEY, P.M.; DIXEN, R.A. (Eds.). Biochemistry of storage carbohydrates in green plants. London: Academic, 1985. p.1-48.

LEGENDRE, B.L. Ripening of sugarcane: effects of sunlight, temperature, and rainfall. Crop Sci, v.15, p.349-352, 1975.
LINGLE, S.E. Sugar metabolism during growth and development in sugarcane internodes. Crop Sci, v.39, p.480-486, 1999.

MARTINS, M.B.G.; CASTRO, P.R.C. Efeito da giberelina e ethefon na anatomia de plantas da cana-de-açúcar. Pesq Agrop Bras, v.34, n.10, p.1855-1863, 1999.

RESENDE, P.A.P. et al. Moddus ${ }^{\circledR}$, a plant growth regulator and management tool for sugarcane production in Brazil. Int Sugar J, v.102, p.5-9, 2000.

RICARDO, C.P.P.; D. SOVIA. Development of tuberous roots and sugar acumullation as related to invertase activity and mineral nutrition. Planta, v.118, p.43-55, 1974.

RICARDO, C.P.P.; AP REES, T. Invertase activity during the development of carrot roots. Phytoch, v.9, p.239-247, 1970. Disponível em: http://www.sciencedirect.com/ science?_ob=ArticleURL\&_udi=B6TH7-42HX8YN9D\&_user $=687358 \&$ rdoc $=1 \&$ fmt $=\&$ \& orig $=$ search \&_sort $=\mathrm{d} \&$ $\mathrm{v}$ i e $\mathrm{w}=\mathrm{c} \& \&_{-}$a c c t $=\mathrm{C} 000037899 \&$ _ version $=1 \&$ u r 1 V e r s i o n $=0 \&$ u s e r i d $=68$ 7358\&md5=52ee203503585adb827b0 $\bar{c} d 87 d 7 a 66 d 8$. Doi: 10.1016/S0031-9422(00)85130-4.

ROITSCH, T.; GONZÁLEZ, M. C. Function and regulation of plant invertases: sweet sensations. Trends Plant Sci, v.9, n.12, 2004. Disponível em: http://www.sciencedirect.com/ science?_ob=ArticleURL\&_udi=B6TD1-4DPGXT8-

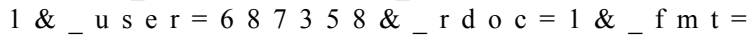
$\&_{-}$or ig $=$s e a r c h \& s o r t $=$d \& vi e w $=$c \& 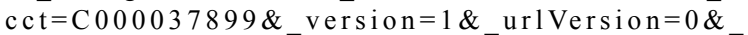 userid $=687358 \& \mathrm{md} 5=6 \overline{2} \mathrm{e} 46390 \mathrm{~b} 934212 \mathrm{a} 5 \mathrm{e} 59 \mathrm{ec} 8 \mathrm{~b} 8630 \mathrm{baed}$. Doi: $10.1016 /$ j.tplants.2004.10.009.

ROSE, S.; BOTHA, F.C. Distribution patterns of neutral invertase and sugar content in sugarcane internodal tissues. Plant Physiol Biochem, v.38, p.819-824, 2000. Disponível em: http://www.sciencedirect.com/ science?_ob=ArticleURL\&_udi=B6VRD-41SSWND$2 \&$ _user $=687358 \&$ rdoc $=1 \&$ fmt $=$ \&_orig $=$ search\&_sort $=\mathrm{d}$ $\&$ vi e w $=$ c \&_a c ct $=$ C $000037899 \&$ _vers i o $=1$ \&_u r l V e r s i o n $=0 \&$ u s e ri d = 687358 \& md5 $=4098254 a 493$ e1599c5c6c7b3821901e3. Doi: 10.1016 / S0981-9428(00)01190-6.

SU, L.Y. et al. The relationship of glyphosate treatment to sugar metabolism in sugarcane: new physiological insights. J Plant Physiol, n.140, p. 168-173, 1992

SUZUKI, J. Biossíntese e acúmulo de sacarose em canade-açúcar (Saccharum spp.): Influência do íon Potássio durante diferentes estádios de crescimento em solução nutritiva. 1983. 96f. Tese (Doutorado em Solos e Nutrição de Plantas) - Escola Superior de Agricultura "Luiz de Queiroz", Universidade de São Paulo, Piracicaba.

TERAUCHI, T. et al. Activity of sucrose phosphate synthase in relation to sucrose concentration in sugarcane internodes. Jpn J Trop Agric, v.44, n.3, p.141-151, 2000.

TYMOWSKA-LALANNE, Z.; KREIS, M. The plant invertases: physiology, biochemistry and molecular biology. Adv Bot Res, v.28, p.71-117, 1998. 
VIEIRA, I.M.S. Efeito do Potássio sobre a atividade de invertases, teores de açúcares e compostos nitrogenados em cana-de-açúcar (Saccharum spp. var. NA56-79) cultivada em solução nutritiva. 1983. 97f. Dissertação (Mestrado) - Escola Superior de Agricultura "Luiz de Queiroz", Universidade de São Paulo, Piracicaba.

VIEIRA, I.M.S. et al. Níveis de açúcares e atividade de invertases em cana-de-açúcar (Saccharum officinalis spp.). I. Cultivares 'NA56-79' e 'CB41-76'. Rev Agric (Piracicaba), v.71, n.1, p.67-92, 1996a.
VIEIRA, I.M.S. et al. Níveis de açúcares e atividade de invertases em cana-de-açúcar (Saccharum spp.). II. Cultivares 'SP701143' e 'SP71-799'. Rev Agric (Piracicaba), v.71, n.2, p.197$224,1996 b$

ZHU, Y.J. et al. Sucrose accumulation in the sugarcane stem is regulated by the difference between the activities of soluble acid invertase and sucrose phosphate synthase. Plant Physiol, v.115, p.609-616, 1997. 